\title{
DA JUSTIFICAÇÃO À EMANCIPAÇÃO: \\ ANOTAÇÕES SOBRE O PAPEL DA NOVA CRÍTICA DA SOCIOLOGIA JURÍDICA EM TEMPOS DE GLOBALIZAÇÃO
}

\section{Thiago Lima Breus}

RESUMO: Destina-se o presente estudo ao exame do papel da Sociologia Jurídica na contemporaneidade, o qual se alterou profundamente após o advento da Globalização de índole neoliberal, pois esta abalou todos os pilares sobre os quais fora edificado o pensamento sociológico moderno, como a determinação do papel social do indivíduo na esfera pública, a solidariedade que une os múltiplos agrupamentos sociais e a idéia de Estado-nação, que coincidia com a noção de sociedade. Propõe, por conseguinte, a concepção de uma nova crítica da Sociologia Jurídica, consoante as teorizações de Enrique Dussel - com um alicerce marxista que promova o apontamento das vítimas causadas pela sociedade e pelas construções teóricas sociológicas tradicionais voltadas mais à justificação teórica das desigualdades do que propriamente à sua superação. 


\section{DELINEAMENTO INICIAL}

É de difícil refutação o fato de que, na contemporaneidade, as transformações ocorridas na sociedade - cada vez mais rápidas, imprevisíveis e paradoxais - sugerem demonstrar que as teorizações não dão mais conta do que se passa na realidade. A busca incessante, que caracteriza a modernidade, do cálculo e da previsibilidade, acabou por encontrar a contingência e a complexidade da sociedade do risco ${ }^{1}$ presente. Sob esta perspectiva, Boaventura de Sousa Santos afirma que "(...) a rapidez, a profundidade e a imprevisibilidade de algumas transformações recentes conferem ao tempo presente uma característica nova: a realidade parece ter tomado definitivamente a dianteira sobre a teoria". ${ }^{2}$

Pode-se afirmar que a complexidade e contingência social, a imprevisibilidade, a rapidez e o antagonismo dos fatos e acontecimentos sociais encontram o seu ápice simultaneamente com a alocação do paradigma da globalização - sob substrato neoliberal - enquanto o único meio e fundamento para a regência e para o estabelecimento da sociedade, acabando por abalar as quase que a totalidade das fundações teóricas do Estado, do Direito e da própria Sociedade.

Este é o pano de fundo sobre o qual o presente escorço pretende examinar o papel da Sociologia Jurídica - e da sua crítica - na atualidade, demonstrando que, nada obstante, a necessidade do estudo dos autores clássicos do pensamento social e suas respectivas escolas - funcionalista, estruturalista e sistêmica porquanto ainda forneçam elementos fecundos para a análise de muitos dos problemas atuais, evidencia-se a necessidade da busca de novos modelos e paradigmas de reflexão para o encaminhamento das emergentes questões sociais, as quais, necessitam de respostas não apenas de ordem prática, mas e ao mesmo tempo, de matriz teórica, capazes de sobrepujar as desigualdades e as negações produzidas socialmente, reduzindo o caminho à almejada emancipação social.

\footnotetext{
${ }^{1}$ Nesse sentido, esclarecedora a posição exarada por Raffaele De Giorgi em: O Risco na Sociedade Contemporânea. In: Revista Seqüência. no 28, junho de 1994. p. 45 e seguintes e Estado y Derecho a Finales Del Siglo. In: Crítica Jurídica. no 17, ano 2000. p. 91-100.
} 
Toma-se, por conseguinte, como referenciais centrais para a construção da análise a seguir desenvolvida, as teorizações de Boaventura de Sousa Santos e de Enrique Dussel, bem como do pensamento da Teoria do Conflito Social e da Teoria Crítica levada a efeito pelos autores da Escola de Frankfurt.

\section{O PENSAMENTO SOCIAL: PRINCÍPIO E CONSOLIDAÇÃO}

As primeiras reflexões sobre o que se pode denominar de social principiaram por uma busca dos indivíduos na compreensão dos fenômenos que regiam a sociedade, não se iniciando, em geral, nas academias e Universidades. Estas reflexões buscavam, por meio de uma explicação racional, a compreensão da ordem de coisas que conformava a estruturação social. No plano teórico, pode-se sustentar, não havia fixação a leis rígidas, imutáveis, de causa e efeito. As suas características essenciais, influenciadas pelo pensamento positivista, ascendente nos primórdios do pensamento social, eram a exterioridade, a imanência, o pragmatismo e o caráter empírico.

Exemplo evidente destas características são as teorizações sobrre o chamado Direito Vivo ${ }^{3}$ elaboradas por Eugen Ehrlich, demonstrando as origens de um pensamento social fruto da análise empírica, a partir da observação de que para além do Direito estatal, existe um Direito reiterado a partir das práticas sociais.

É possível afirmar que a sociedade passa a ser um objeto delimitado de estudo das academias a partir das teorizações de Émile Durkheim, que pretendeu alocar o estudo da sociedade como uma ciência. ${ }^{4}$ São representativas disto as considerações do autor francês sobre o Direito como manifestação da solidariedade - mecânica ou orgânica - que integra os indivíduos no meio em que vivem.

Nesse sentido, argumenta Florestan FERNANDES:

"A teoria de Durkheim possui, em conjunto, um grande mérito. Este consiste na preocupação sistemática de isolar e fundamentar, logicamente, a partir dos quais são

2 SANTOS, Boaventura de Sousa. Para um novo senso comum: a ciência, o direito e a política na transição paradigmática. $3^{\underline{a}}$ ed., São Paulo: Cortez, 2001. p. 29.

${ }^{3}$ EHRLICH, Eugen. Fundamentos da Sociologia do Direito. Brasília: UnB, 1986. p. 373.

${ }^{4}$ Exemplo disto pode ser verificado em DURKHEIM. Émile. Divisão do trabalho social e direito. In: SOUTO, Cláudio. FALCÃO. Joaquim. Sociologia e direito: leituras básicas de sociologia. São Paulo: Livraria Pioneira, 1980. p. 123 e RODRIGUES, José Albertino (org.). Durkheim. 6ªe ed., São Paulo: Ática, 1993. p. 48. 
discutidos os demais problemas da indução causal e da indução funcional na sociologia. Dessa maneira, o exame da adequação dos dois tipos de indução e de generalização subordina-se, diretamente, às implicações essenciais do ponto de vista sociológico. Pôde, assim, evitar os falsos problemas, que decorreriam da preocupação inversa: a de caracterizar o ponto de vista sociológico a partir do metido de interpretação adotado e de suas implicações lógicas. O ponto de vista sociológico define, de fato, a perspectiva através da qual o sujeito encara a realidade e procura explicá-la cientificamente, tomando em consideração a natureza mesma dos fenômenos sociais. A análise das causas e a análise das funções sociais constituiriam os meios de investigação capazes de conduzir, de acordo com as propriedades e as condições dos fenômenos considerados, a aplicação daquele ponto de vista à explicação científica da realidade social”. 5

São fundamentais, porém, para a constituição do pensamento sociológico moderno, as contribuições teóricas levadas a efeito por Max Weber. São de autoria do autor alemão, as principais categorias que possibilitam uma análise acurada da realidade social, como, em linhas gerais: (i) a compreensão do sentido da ação individual que se traduz na ação social dotada de sentido; (ii) a compreensão, que se exprime da apreensão interpretativa do sentido da ação; (iii) a questão da causalidade e da multicausalidade, como a classificação dos fenômenos, não necessariamente classificados hierarquicamente, mas que convergem para a produção dos fatos sociais; (iv) as noções de tipo ideal, de poder e de dominação (Herrschaft) e (v) a explicação dos sentidos que orientam a ação individual.

São essas as principais construções teóricas que acabaram por fundamentar o pensamento social moderno, que visava, genericamente, explicar as funções e a estrutura social, daí advindo a formação das escolas funcionalista e estruturalista do pensamento social.

A preocupação destas escolas com o estabelecimento de regras abstratas, com a análise do tipo de direito prevalecente em determinado meio social e com a verificação dos papéis sociais acabavam deixando de lado preocupações com os próprios fundamentos deste direito e com o seu próprio conteúdo.

Todas essas apreciações teóricas de ordem formal, sobre a conformação do corpo social e a sua estruturação racional acabaram delineando o pensamento sociológico tradicional, para o qual o rigor metodológico e a utilidade social da

${ }^{5}$ FERNANDES, Florestan. Fundamentos Empíricos da Explicação Sociológica. São Paulo: Nacional, 1972. p. 195. 
sociologia pressupõem que ela se detenha no exame do que existe e não nas alternativas ao já existente e, na idéia "de que o cientista social não pode impor as suas preferências normativas por carecer de um ponto de vista privilegiado para o fazer". 6

\section{A TEORIA DO CONFLITO SOCIAL}

O marxismo é, provavelmente, a teoria estrutural da sociedade que exerceu maior influência no pensamento sociológico moderno. Ao contrário dos autores anteriormente mencionados, a principal preocupação teórica de Karl Marx foi o apontamento das razões implícitas determinantes para a estruturação social de sua época, bem como a indicação das vítimas que esta estrutura causava. Passaram ao largo do objeto de estudo de Karl Marx, as questões relativas ao equilíbrio social e o estabelecimento da harmonia coletiva, objeto das pesquisas e objetivo das teorizações de Émile Durkheim, haja vista que o pensamento marxista volta-se à demonstração da impossibilidade de estabilização social em razão da luta de classes.

Embora a construção teórica marxista não seja mais atual no concernente à transformação do capitalismo e a sua superação, bem como não se possa, contemporaneamente, admitir que haja um princípio único de transformação social, como um futuro socialista gerado pelo desenvolvimento constante da força produtiva e da luta de classes que ela produz, os principais aportes teóricos marxistas não podem ser tangenciados, motivo pela qual serão expostos sucintamente a seguir, sem descurar da complexidade da teoria sob exame. Segundo Juan Carlos Agulla, esta complexidade se produz, em primeiro lugar, porque Marx é uma personalidade intelectual de primeira categoria e, em segundo lugar, porque sua obra é extremamente extensa e está dispersa em uma grande quantidade de livros e não guarda sempre uma coerência devido às contradições que surgem da necessidade de dar uma resposta adequada aos múltiplos problemas de sua época. ${ }^{7}$

\footnotetext{
${ }^{6}$ SANTOS, Boaventura de Sousa. Ob cit., p. 25.

${ }^{7}$ AGULLA. Juan Carlos. Teoría Sociológica. Buenos Aires: Depalma, 1987. p. 87.
} 


\subsection{A Idéia da Superação Dialética Marxista}

Para que se possa compreender de maneira adequada a noção da dialética no pensamento marxista, necessário se faz anterior apreciação desta metodologia em Hegel, que inspirou sobremaneira Karl Marx e Friedrich Engels na formação da sua compreensão sobre a história.

Antes então do exame da superação dialética, convém a verificação de alguns conceitos-chave para a sua caracterização.

Hegel - influenciado pelo ideário da Revolução francesa, em que o homem passou a ser qualificado enquanto um sujeito histórico e essencialmente ativo, que interfere e altera a sua realidade - verifica que é o trabalho que é a mola propulsora do desenvolvimento humano, que serve de instrumento para a transformação da realidade humana.

Essa noção idealizada de trabalho, é que servirá para a sua conceituação de superação dialética.

Como expressão da sua concepção de superação dialética, HEGEL se utiliza do vocábulo alemão Aufheben que, possui três significados distintos: $O$ primeiro de anular, cancelar (ex. cancelar um passeio, por mal tempo). O segundo sentido é o de erguer alguma coisa e mantê-la erguida e protegida. (Ex. ficou suspenso no ar, intacto). O terceiro sentido, por sua vez, é o de elevar a qualidade, de promover a passagem de alguma coisa para um nível superior (ex. suspender o nível).

Hegel, então, utiliza a palavra Aufheben nos três sentidos ao mesmo tempo. Para ele a superação dialética é simultaneamente a negação de uma determinada realidade, a conservação de algo essencial que exista nessa realidade negada e a elevação dela a um nível superior.

Essa explicação hegeliana sobre a dialética é considerada abstrusa pela crítica sociológica e se deve ao fato de Hegel era um autor filiado ao idealismo abstrato. A perspectiva da dialética, porém, traçada por Marx e Engels, por serem autores estritamente materialistas, é qualificada como a mais adequada sobre o fenômeno.

Karl Marx não chegou a escrever uma obra sobre a sua noção de dialética, contudo, pretendia escrevê-la expondo a sua concepção de superação dialética 
material, chegando inclusive a anunciar, em dezembro de 1875 esta sua intenção, embora não chegou a concretizá-la.

Enquanto Karl Marx escrevia O Capital, Friedrich Engels redigiu diversas anotações sobre o conceito que compartilhava com Marx sobre a dialética e a defesa do seu caráter material em oposição à compreensão dialética idealista de Hegel.

Friedrich Engels, por conseguinte, estabeleceu três leis essenciais para definir o que seria a dialética: i) lei da passagem da quantidade á qualidade (o ser é sempre um vir a ser); ii) Lei da interpenetração dos contrários (tese, atntítese, síntese, se faz necessário o conhecimento da totalidade); iii) Lei da negação da negação (a dinâmica é a superação dialética).

A concepção marxista da dialética pressupõe, ainda, o conhecimento de alguns outros conceitos, são eles: a contradição, para o qual as coisas devem ser compreendidas pelo seu oposto (riqueiza/pobreza); mediação (da aparência/à essência) e a totalidade (sempre existe um grau/nível maior de totalidade que nunca será esgotado).

A noção de dialética foi um dos conceitos mais trabalhados pelos autores marxistas, A noção levada a efeito por Ernst Bloch merece ser mencionada, pois assegura que "o método dialético nos incita a revermos o passado à luz do que está acontecendo no presente; ele questiona o presente em nome do futuro, o que está sendo em nome do que "ainda não é". 8

Bertolt Brecht também traz uma concepção peculiar de superação dialética: "O que é, exatamente por ser tal como é, não vai ficar como está" 9

A concepção de superação dialética em Marx, central para a compreensão de sua teoria e que permanece atual, relaciona-se diretamente á noção, a seguir exposta, do materialismo histórico e se apresenta em sua essência na décimaprimeira tese sobre Feuerbach: "Os filósofos têm se limitado a interpretar o mundo; trata-se no entanto, de transfomá-lo".

\footnotetext{
${ }^{8}$ KONDER. Leandro. O que é Dialética. 18ª ed., São Paulo: Brasiliense, 1988. p. 84.

9 lbid. p. 75
} 


\subsection{O Materialismo Histórico}

Embora a expressão denomine toda a concepção marxista acerca da história e da sua concretização e construção pelo trabalho do homem, ela, como expressão, nunca foi utilizada por Karl Marx. Friedrich Engels a utilizou pela primeira vez tão somente após a morte de Marx, para denominar a concepção que tinham acerca da história.

Para Marx, a história é um processo de criação, satisfação e recriação contínua das necessidades humanas. É isso que distingue o homem dos animais, cujas necessidades são fixas e imutáveis. É por essa razão que o trabalho, o intercâmbio criador entre os homens e o seu ambiente natural está na base da sociedade humana. A relação entre o indivíduo e o seu ambiente natural estabelecese por mediação das características particulares da sociedade a que pertence. Para Marx, quando pretendemos estudar a evolução da sociedade humana, temos de partir do exame empírico dos processos concretos da vida social que constituem condição sine qua non da existência humana.

Para Walter Benjamim, "a história, tal como ela veio se desenrolando até o presente, está impregnada de violência, de opressão de barbárie; e é exatamente por isso que a tarefa do teórico do materialismo histórico não pode ser pensar uma espécie de prolongamento 'natural' desta história, não pode ser promover a continuidade daquilo que essa história produziu, limitando-se a transmitir seus produtos de mão em mão. Um espírito dialético, argumenta o autor, insiste em 'escovar a história a contrapelo'."10

Nas palavras de Engels, o materialismo histórico significaria: "para designar esta concepção da história universal que demonstra a causa final e a força propulsora decisiva de todos os acontecimentos históricos importantes no desenvolvimento econômico da sociedade e as transformações do modo de produção e de mudança e a conseguinte divisão da sociedade em distintas classes e as lutas destas classes em si".

\footnotetext{
${ }^{10}$ KONDER. Leandro. O que é Dialética. 18ª ed., São Paulo: Brasiliense, 1988. p. 70.
} 


\subsection{Infra-estrutura e superestrutura}

Outra conceituação-chave do marxismo é a divisão da estrutura social em infra-estrutura e super estrutura, como se formasse um edifício, em que a superestrutura está apoiada e é dependente da infra-estrutura. Para Karl Marx a expressão infra-estrutura diz respeito à totalidade das relações de produção, (que serão examinadas na seqüência), e que constituem a estrutura econômica da sociedade.

A superestrutura, por sua vez, representa a dimensão jurídica e política da sociedade e, por conseguinte, as formas de consciência sociais.

Existe, por conseguinte, uma preeminência ontológica da infra-estrutura para a superestrutura, que se manifesta na expressão marxista de que "não é a consciência do homem que determina o seu ser, mas ao contrário, é o seu ser social que determina a sua consciência".

Há, por conseguinte, uma dependência e um condicionamento da superestrutura pela infra-estrutura ou estrutura, haja vista que aquela serve sempre como mecanismo de controle social com a finalidade de manter a estrutura.

Segundo Marx, a infra-estrutura (forças produtivas materiais) é base na qual se alicerçam estas relações de produção (que são a expressão jurídica com as relações de propriedade existentes). Nas palavras do pensador alemão:

"Na produção social da própria existência, os homens entram em relações determinadas, necessárias, independentes de sua vontade; estas relações de produção correspondem a um grau determinado de desenvolvimento de suas forças produtivas materiais. A totalidade dessas relações de produção constitui a estrutura econômica da sociedade, a base real sobre a qual se eleva uma superestrutura jurídica e política e à qual correspondem formas sociais determinadas de consciência. O modo de produção da vida material condiciona o processo da vida social, política e intelectual. Não é a consciência dos homens que determina o seu ser; ao contrário, é o seu ser social que determina a sua consciência. Em certa etapa de seu desenvolvimento, as forças produtivas materiais da sociedade entram em contradição com as relações de produção existentes, ou, o que não é mais que sua expressão jurídica, com as relações de propriedade existentes, ou, o que não é mais que 
sua expressão jurídica, com as relações de propriedade no seio das quais elas se haviam desenvolvido até então". ${ }^{11}$

\subsection{A Alienação e o Conceito de Ideologia}

Para Marx, o trabalho alienado é aquele no qual o produtor não pode se reconhecer no produto de seu trabalho, porque as condições desse trabalho, suas finalidades reais e seu valor não dependem do próprio trabalhador, mas do proprietário das condições do exercício do trabalho. Este conceito está intrinsecamente relacionado à noção de ideologia em Marx, que se trata de um conceito que tem por função manter a dominação das classes dominantes sobre as dominadas, ou seja, trata-se de uma visão invertida passada pelas classes dominantes para as classes dominadas com o intuito de perpetuar a dominação.

Segundo Marilena Chauí, o que torna possível a ideologia é a luta de classes, a dominação de uma classe sobre as outras. Porém o que faz da ideologia uma força quase impossível de ser destruída é o fato de que a dominação real é justamente aquilo que a ideologia tem por finalidade ocultar. Em outras palavras, a ideologia nasce para fazer com que os homens creiam que suas vidas são o que são em decorrência da ação de certas entidades (natureza, os deuses ou Deus, a ciência, a sociedade, o estado) que existem por em si e por si e às quais é legítimo e legal que se submetam. Ora, além disso, como a experiência vivida imediata e a alienação confirmam tais idéias, a ideologia simplesmente cristaliza em "verdades" a visão invertida do real. O seu papel, portanto, é o de fazer com que os homens creiam que tais idéias representam efetivamente a realidade. E, por fim, também e o seu papel fazer com que os homens creiam que essas idéias são autônomas (não dependem de ninguém) e representam realidade autônomas (não foram elaboradas por ninguém). ${ }^{12}$

${ }^{11}$ MARX. Karl. Teoria e Processo histórico da revolução social (prefácio á contribuição à crítica da Economia Política. In: MARX/Engels - História, Coleção Grandes Cientistas Sociais, FERNANDES, Florestan (org). São Paulo: Ática, 1987. p. 231-235.

12 CHAUÍ, Marilena. O que é Ideologia. São Paulo: Brasiliense, 1980. p. 37 


\subsection{Classe social e Luta de Classe}

Por classe, deve-se entender um fenômeno histórico que deve ser compreendida como a relação em que alguns homens, como resultado de experiências comuns que sentem e articulam a identidade de seus interesses entre si, e contra outros homens cujos interesses diferem e geralmente se opõem aos seus. A consciência de classe, por sua vez, é a formada pelo modo de como as experiências comuns dos membros da classe são tratadas em termos culturais: tradições, sistemas de valores, idéias e formas institucionais.

As classes sociais não são coisas, nem idéias, mas são relações sociais determinadas pelo modo como os homens, nas produções de suas condições materiais de existência, se dividem no trabalho, instaurando formas determinadas da propriedade, reproduzem e legitimam aquela divisão e aquelas formas por meio das instituições sociais e políticas, representam para si mesmos o significado dessas instituições através de sistemas determinados de idéias que exprimem e escondem o significado real de suas relações. As classes sociais são o fazer-se classe dos indivíduos em suas atividades econômicas, políticas e culturais.

Este é outro conceito que merece destaque no conjunto da obra de Marx. Alguns intérpretes de Marx, comumente dizem que a mecânica do movimento da história, em Marx, é a luta de classes. Outros autores, porém, como Juan Carlos Agulla, interpretam esta do seguinte modo: a luta entre as classes é um conflito político voluntarista, mas este conflito social não é entre as classes mas entre os sistemas estratificação social. Nesse sentido, o primeiro seria um problema político que move a história e o outro, o de conflito, que é um problema sociológico e que define a sociedade.

\section{TEORIA TRADICIONAL E TEORIA CRÍTICA: A ESCOLA DE FRANKFURT}

A expressão Teoria Crítica remete imediatamente ao fio-condutor teórico aglutinador dos pesquisadores que constituíam a primeira geração da Escola de Frankfurt, alicerçado nas categorias do pensamento Marxismo acima explicitadas. Pode-se afirmar que a Escola de Frankfurt, no início dos anos 30, se pautava por dois manifestos. O primeiro, ficou conhecido como "materialismo interdisciplinar". O 
segundo manifesto perpassa pelo artigo elaborado por Max Horkheimer, em 1937, denominado de "Teoria Tradicional e Teoria Crítica, assim como nas observações sobre ele levadas a efeito por Herbert Marcuse em "Filosofia e Teoria Crítica". ${ }^{13}$ Esses manifestos orientaram as pesquisas do Instituto que congregava os frankfurtianos, funcionando como uma espécie de ferramenta geral para a implementação do propósito de renovar o marxismo e aprofundar a compreensão da sociedade contemporânea. ${ }^{14}$

Em "Teoria Tradicional e Teoria Crítica", Max Horkheimer promove a proposição da Teoria Crítica, a partir de uma restauração do método dialético marxista em oposição ao pensamento social tradicional. Ele se utiliza do vocábulo "crítica", no mesmo sentido que Karl Marx o utilizou no O Capital, que tem por subtítulo Crítica da Economia Política, e não no sentido Kantiano da acepção da Crítica da Razão Pura. Com isso, Max Horkheimer restabelece a prioridade da crítica da sociedade moderna burguesa como um aspecto essencial ao marxismo. Além disso, determina-o por meio de um método que confronta, pela via da crítica imanente, as promessas dessa sociedade como suas relações. ${ }^{15}$

A influência marxista na produção teórica dos autores da primeira fase da Escola de Frankfurt pode ser notada na seguinte passagem extraída da obra de Max Horkheimer:

"A teoria crítica não se deixa enganar pela aparência, isto é, pela ilusão fomentada meticulosamente nas ciências sociais, de que propriedade e lucro não desempenhariam um papel decisivo. De um lado, a teoria crítica jamais viu as relações jurídicas como essência. Ao contrário, considera-as como a superfície do contexto social e sabe que a disposição sobre homens e coisas permanece nas mãos de um grupo específico da sociedade, que na verdade concorre menos no próprio pais, mas que se encontra numa concorrência cada vez mais acirrada com outros poderosos grupos econômicos no plano internacional. O lucro provém das mesmas fontes sociais que antes, e tem que ser aumentado de forma costumeira. Por outro lado, parece desaparecer junto com a eliminação de todo direito de conteúdo determinado, fruto da concentração de poder econômico e realiza plenamente nos

${ }^{13}$ MUSSE., Ricardo. As Raízes Marxistas da Escola de Frankfurt. In: A Escola de Frankfurt no Direito. Curitiba: Edibej, 1999. p. 24.

\footnotetext{
${ }^{14}$ Id.

15 Ibid. p. 25.
} 
Estado autoritários uma ideologia aliada a um fato cultural que ao lado de seu aspecto negativo tem também um caráter postivo". ${ }^{16}$

A atenção, por Max Horkheimer e pelos demais pesquisadores da Escola de Frankfurt privilegia a compreensão da distorção estruturante da sociedade, a qual faz com que exista e apareça como normal para os indivíduos, compatibilidade entre coisas tão dispares como as mercadorias e o tempo (de trabalho) humano. ${ }^{17}$

Esta perspectiva, levada a efeito pelos pesquisadores frankfurtianos, a partir do resgate da crítica marxista, apresenta-se como um instrumento importante para a análise do fenômeno contemporâneo da Globalização, que coloca em questão todos os pilares da epistemologia desenvolvida sobre o Estado, o Direito e a própria Sociedade, como ilustrado no tópico seguinte.

\section{O FENÔMENO GLOBALIZANTE}

Argumenta Abili Lázaro Castro de Lima que a globalização teve várias concepções ao longo do tempo, podendo ser encontradas atualmente, múltiplas significações para o mesmo fenômeno, como a dimensão econômica, a política, a social, a ambiental, a cultural, dentre outras. ${ }^{18}$

O estudo sociológico da Globalização encontra um óbice espistemológico destacado por Octavio lanni, consistente no fato de que a Sociologia sempre teve o centro de suas reflexões localizado no âmbito do Estado nacional, sendo este, exatamente, a localização da maior alcance do fenômeno de mundialização. Consoante $\mathrm{o}$ autor, os desafios epistemológicos suscitados pela formação e transformação da sociedade nacional, alimentaram a emergência e continuam a alimentar o desenvolvimento das ciências sociais, constituindo os fundamentos de seu patrimônio. A maior parta dos conceitos, categorias e leis formulados pelas ciências sociais tem por base as relações, os processos e as estruturas de

\footnotetext{
${ }^{16}$ HORKHEIMER, Max. Direito Natural e Ideologia. In: Origens da filosofia burguesa da história. Lisboa: Presença, 1982. p. 41.

17 MUSSE, Ricardo. Ob cit. p. 25.

18 LIMA, Abili Lázaro Castro de. Globalização Econômica, Política e Direito: Análise das Mazelas Causadas no Plano Político-Jurídico. Porto Alegre: Sergio Antonio Fabris Editor, 2002. p. 11.
} 
dominação e apropriação, integração e antagonismo, soberania e hegemonia peculiares à realidade nacional. ${ }^{19}$

Na mesma linha, persiste Octavio lanni:

"As principais teorias da sociedade, tais como a evolucionista, positivista, funcionalista, marxista, weberiana, estruturalista e sistêmica, entre outras, tomam por base relações, processos e estruturas próprios da sociedade nacional, como um todo ou em alguns dos seus aspectos. Apoiadas nessas teorias, a economia, política, geografia, demografia, sociologia, antropologia e história, entre outras ciências sociais, constituíram e continuam a constituir uma parte importância de seu patrimônio teórico. A sociologia, conforme ela aparece no seio da civilização ocidental e como a conhecemos hoje, é endemicamente preocupada com o nacional. Não reconhece uma totalidade mais ampla que a organizada politicamente na nação. O termo 'sociedade' como tem sido usado por sociólogos, independentemente da filiação teórica, é para todos os fins práticos o nome de uma entidade idêntica, em tamanho e composição, ao estado-nação". 20

A incapacidade da teoria sociológica tradicional, no exame da globalização decorre ainda do fato de que esta abala todos os pilares sobre os quais foi edificado o pensamento social ao longo dos séculos XIX e XX. Argumenta Abili Lázaro Castro de Lima que o panorama da globalização "deflagrou um processo no qual assistimos à gradual erosão da soberania, à obsolência das fronteiras nacionais, ao retraimento da esfera pública em favor do mercado, à perda dos direitos políticos dos cidadãos como resultado do esvaziamento da sua participação política, peculiaridades que são indicativas da crise e/ou declínio do Estado-nação". ${ }^{21}$

Com a diminuição da participação política ocorrida inclusive em função do distanciamento dos cidadãos do centro decisório, que deixa de ser local, o cidadão assume o papel tão-só de consumidor, despertando comportamentos, consoante Abili Lázaro Castro de Lima, de individualismo e egoísmo, que rompem os elos de solidariedade na sociedade, com a perda do sentimento dos cidadãos de possuírem um destino comum, resultado em fragmentação social. ${ }^{22}$

19 IANNI. Octávio. Nação e Globalização. In: Milton Santos. Fim de Século e Globalização. 3ª̣ed., São Paulo: Hucitec, 1997. p. 68.

\footnotetext{
${ }^{20} \mathrm{Id}$.

${ }^{21}$ LIMA, Abili Lázaro Castro de. Ob cit. p. 23.

22 Ibid. p. 24.
} 
José Eduardo Faria enumera os eventos a que os Estados nacionais estão submetidos pela globalização e que colocam em xeque grande parte das teorizações sociais desenvolvidas para a explicação do comportamento dos agentes sociais no âmbito da civilização, que até pouco tempo atrás ajustava-se à esfera da nação:

"(a) os Estados nacionais têm comprometida sua capacidade de coordenação macroeconômica, (b) perdem as condições materiais estabelecer critérios políticos e dispositivos jurídicos aptos a permitir a superação da rigidez da lógica econômica na busca do bem-estar coletivo, (c) revelam-se incapazes de impedir a transferência de parte de seu poder decisório para as áreas de influência do capital privado e dos grandes conglomerados empresariais, (d) enfrentam dificuldades para assegurar a eficácia de seus instrumentos de política industrial baseados na imposição de restrições aos fluxos de capitais e mercadorias e, por fim, (e) dispõem de poucas condições políticas e financeiras para administrar o custo social da transformação das relações entre capital e o trabalho provocada pela substituições do antigo paradigma fordista pelo novo paradigma da especialização flexível da produção". 23

Há ainda um elemento peremptório dentre os apresentados com o advento da Globalização de índole neoliberal, que põe em questão os estudos sobre a sociedade e sua estruturação levados a efeito até então. Ignacio Ramonet o destaca: "o mais grave na globalização é, evidentemente, o fato de condenar de antemão, em nome do 'realismo', toda veleidade de resistência ou mesmo de dissidência. Assim sendo, são considerados infames ou definidos como 'populistas’, quaisquer sobressaltos republicanos, quaisquer buscas de alternativas de regulação democrática, quaisquer críticas ao mercado". ${ }^{24}$

Expostas brevemente as mazelas causadas pela globalização, impõe-se o exame das proposições, consoante Boaventura de Sousa Santos e Enrique DUSSEL, para o papel crítico da Sociologia Jurídica na atualidade.

\footnotetext{
${ }^{23}$ FARIA, José Eduardo. Democracia e Governabilidade: os direitos humanos à luz da globalização econômica. In: FARIA. José Eduardo (org.) Direito e Globalização Econômica. São Paulo: Malheiros, 1996. p. $141-142$.

24 RAMONET. Ignacio. O pensamento único e os regimes globalitários. In: FIORI. José Luis. Et alii. Globalização: o fato e o mito. Rio de Janeiro: UERJ, 1998. p. 58.
} 


\section{A SOCIOLOGIA JURÍDICA CONTEMPORÂNEA: A NECESSIDADE DO APONTAMENTO DAS NEGATIVIDADES E A AFIRMAÇÃO DAS VÍTIMAS}

Verificadas as questões que a globalização impõe ao pensamento sociológico, colocando em xeque quase que a totalidade dos seus alicerces, necessário se faz investigar o novo papel que a sociologia jurídica assume na atualidade. Nota-se que, nesta perspectiva, a globalização impõe um ponto de ruptura às teorizações sociais, porquanto necessitam se revolucionar para dar explicações adequadas a este novo fenômeno social.

A Teoria Crítica, alicerçada sobre o pensamento marxista, representa uma mediação fundamental para que se possa examinar adequadamente a realidade contemporânea. Nada obstante isso, já existem teorizações que classificam a teoria crítica enquanto uma teoria tradicional, haja vista que, como o movimento da teoria crítica do Direito, que visava superar aspectos formais para alcançar o conteúdo material do Direito, é possível encontrar conteúdos materiais que apresentam negatividades maiores do que o conteúdo exclusivamente formal.

Sobre a transformação das ciências sociais em meios de crítica e afirmação das negatividades, em especial no mundo periférico, assevera Orlando Fals Borda que é necessário "(...) transformar as ciências sociais em instrumentos de consciência crítica, em fator de autonomia cultural e política e em meio de luta contra a miséria e as desigualdades sociais. Nosso objetivo mais amplo consiste em pôr as ciências sociais a serviço dos direitos fundamentais do homem e da criação de formas autenticas de democracia econômica, social e política". ${ }^{25}$

A nova crítica, por conseguinte, necessita alocar o seu princípio a partir do binômio negação versus afirmação, haja vista que há conteúdos de sociologia, de ordem material, que negam a própria vida humana e outros que, mesmo sem negála, acabam por produzir vítimas, muitas vezes não intencionais, mas que devem ser apontadas pelo estudo social na contemporaneidade.

Sobre esta nova possibilidade de crítica, argumenta Enrique Dussel:

"A validade intersubjetiva crítica que se consegue pelo consenso argumentativo graças à razão discursiva da comunidade simétrica das vítimas, com a articulação da retaguarda dos

25 FALS BORDA. Orlando. Ciencia Propria y Colonialismo intelectual. México: Nuestro Tiempo, 1974. p. 31. 
intelectuais orgânicos (que usam e refundem as ciências sociais e filosofias críticas), confronta assim a antiga validade intersubjetiva hegemônica. A simetria criada entre as vítimas graças à sua dura luta pelo reconhecimento, pelo descobrimento da não-verdade (inclusive com a colaboração do método-científico), da não-validade (pelo procedimento formal-participativo-democrático do estamento das vítimas conscientes, críticas e militantes), da não -eficácia (factibilidade tecnológica, instrumental ou estratégica) diante do sistema hegemônico, abre as portas à criatividade positivas na formulação das utopias possíveis". 26

Sem embargo da necessidade da superação da teoria tradicional para uma nova teoria crítica, Boaventura de Sousa Santos aponta as dificuldades da edificação de uma teórica crítica atualmente:

"As promessas da modernidade, por não terem sido cumpridas, transformaram-se em problemas para os quais parece não haver solução. Entretanto, as condições que produziram a crise da teoria crítica moderna não se converteram ainda nas condições de superação da crise". É daí que decorre, segundo o autor, a complexidade da posição de superação paradigmática, haja vista que "enfrentamos problemas modernos para os quais não há soluções modernas. A solução apontada por Boaventura de Sousa Santos perpassa na adoção de uma posição que ele denomina de pós-modernidade inquietante ou de oposição, na qual a disjunção entre a modernidade dos problemas e a pós-modernidade das eventuais soluções deve ser assumida plenamente e transformada num ponto de partida para enfrentar os desafios da construção de uma teoria crítica pós-moderna”. ${ }^{27}$

A construção de uma teoria sociológica crítica perpassa, por conseguinte, pela adoção de uma posição de oposição, conforme Boaventura de Sousa Santos, apontando as vítimas produzidas pelo sistema globalizante, intencionais ou não e indicando a sua afirmação, como ser humano, e dos seus direito fundamentais.

\section{CONCLUSÃO}

Em linhas gerais, o estudo apresentado objetivou demonstrar a necessidade - imposta pela globalização, que questiona os baldrames fundamentais das Teorias Sociais - da conformação de uma nova teoria crítica social, que não se baste na busca da superação da forma pelo conteúdo, mas que se volte e se funcionalize na

${ }^{26}$ DUSSEL, Enrique. Ética da Libertação na Idade da Globalização e da Exclusão. 2ª ed., Petrópolis: Vozes, 2002. p. 457.

27 SANTOS, Boaventura de Sousa. Ob cit., p.29. 
concretização da emancipação humana. Para tanto, consoante Enrique Dussel, necessário se faz o apontamento das negatividades produzidas pelo sistema-mundo globalizado e a afirmação das suas vítimas, de modo dessemelhante ao efetivado pelas teorias sociais tradicionais, que em busca de um equilíbrio social artificialmente assegurado, acabavam por excluir os indivíduos que dele não participavam.

\section{REFERÊNCIAS BIBLIOGRÁFICAS}

AGULLA, Juan Carlos. Teoría Sociológica. Buenos Aires: Depalma, 1987.

BOTTOMORE, Tom. Dicionário do Pensamento Marxista. Rio de Janeiro: Zahar, 1997.

CHAUÍ, Marilena. O que é Ideologia. São Paulo: Brasiliense, 1980.

DURKHEIM, Émile. Divisão do trabalho social e direito. In: SOUTO, Cláudio. FALCÃO. Joaquim. Sociologia e direito: leituras básicas de sociologia. São Paulo: Livraria Pioneira, 1980.

DUSSEL, Enrique. Ética da Libertação na Idade da Globalização e da Exclusão. $2^{a}$ ed., Petrópolis: Vozes, 2002.

EHRLICH, Eugen. Fundamentos da Sociologia do Direito. Brasília: UnB, 1986. p. 373.

FALS BORDA. Orlando. Ciencia Propria y Colonialismo intelectual. México: Nuestro Tiempo, 1974.

FARIA, José Eduardo. Democracia e Governabilidade: os direitos humanos à luz da globalização econômica. In: FARIA. José Eduardo (org.) Direito e Globalização Econômica. São Paulo: Malheiros, 1996.

FERNANDES, Florestan. Fundamentos Empíricos da Explicação Sociológica. São Paulo: Nacional, 1972.

GIORGI, Raffaele de. O Risco na Sociedade Contemporânea. In: Revista Seqüência. no 28, junho de 1994. p. 45 e seguintes.

Estado y Derecho a Finales Del Siglo. In: Crítica Jurídica. no 17, ano 2000. p. 91-100.

HORKHEIMER, Max. Direito Natural e Ideologia. In: Origens da filosofia burguesa da história. Lisboa: Presença, 1982.

IANNI. Octávio. Nação e Globalização. In: Milton Santos. Fim de Século e Globalização. 3ªed., São Paulo: Hucitec, 1997.

KONDER, Leandro. O que é Dialética. 18ª ed., São Paulo: Brasiliense, 1988. 
LIMA, Abili Lázaro Castro de. Globalização Econômica, Política e Direito: Análise das Mazelas Causadas no Plano Político-Jurídico. Porto Alegre: Sergio Antonio Fabris Editor, 2002.

MARX, Karl. Teoria e Processo histórico da revolução social (prefácio á contribuição à crítica da Economia Política. In: Marx/Engels - História, Coleção Grandes Cientistas Sociais, FERNANDES, Florestan (org). São Paulo: Ática, 1987.

MUSSE, Ricardo. As Raízes Marxistas da Escola de Frankfurt. In: A Escola de Frankfurt no Direito. Curitiba: Edibej, 1999.

RAMONET. Ignacio. O pensamento único e os regimes globalitários. In: FIORI. José Luis. Et alii. Globalização: o fato e o mito. Rio de Janeiro: UERJ, 1998.

RODRIGUES, José Albertino (org.). Durkheim. 6ª ed., São Paulo: Ática, 1993. p. 48.

SANTOS, Boaventura de Sousa. Para um novo senso comum: a ciência, o direito e a política na transição paradigmática. 3ª ed., São Paulo: Cortez, 2001. 